TITLE:

\title{
Attentional cueing induces false memory
}

\author{
AUTHOR(S):
}

Miyoshi, Kiyofumi; Ashida, Hiroshi

\section{CITATION:}

Miyoshi, Kiyofumi ...[et al]. Attentional cueing induces false memory. Consciousness and Cognition 2016, 43: 66-74

\section{ISSUE DATE:}

2016-07-01

URL:

http://hdl.handle.net/2433/219652

\section{RIGHT:}

(C) 2016. This manuscript version is made available under the CC-BY-NC-ND 4.0 license

http://creativecommons.org/licenses/by-nc-nd/4.0/; The full-text file will be made open to the public on 01 July 2018 in accordance with publisher's 'Terms and Conditions for Self-Archiving'.; この論文は出版社版でありません。引用の際に は出版社版をご確認ご利用ください。; This is not the published version. Please cite only the published version. 


\section{Attentional Cueing Induces False Memory}

Kiyofumi MIYOSHI (Corresponding author)

Graduate School of Letters, Kyoto University, Sakyo, Kyoto, 6068501, Japan

TEL: +81-75-753-2753

FAX: $+81-75-753-2835$

E-mail: miyoshi80@gmail.com

\section{Hiroshi ASHIDA}

Graduate School of Letters, Kyoto University, Sakyo, Kyoto, 6068501, Japan

TEL: +81-75-753-2753

FAX: +81-75-753-2835

E-mail: ashida@psy.bun.kyoto-u.ac.jp

\section{Abstract}

The fluency of stimulus processing significantly contributes to recognition memory judgments. We investigated the effect of processing fluency induced by attentional cueing on recognition judgments. Participants performed a Remember/Know recognition test, while their spatial attention was manipulated in the test session. Stimulus location was either predicted (congruent condition) or unpredicted (incongruent condition) using an arrow cue. The results revealed that familiarity-based false recognition increased in the incongruent condition wherein the participants may have attributed part of the perceived disfluency to the attentional cue, and they may have overestimated the fluency for the stimulus, leading to increased false recognition. However, in the congruent condition, the participants may have attributed some parts of the perceived fluency to the attentional cue and underestimated the fluency for the stimulus, leading to decreased false recognition. In sum, stimulus-irrelevant attentional cueing induces unintentional processing about the source of fluency and biases recognition memory.

Keywords: recognition memory, memory illusion, processing fluency, attentional cueing This is the accepted version of the article,which has been published in final form at http://www.sciencedirect.com/science/article/pii/S1053810016300885. 


\section{Introduction}

Human memory has been extensively investigated using recall and recognition tests (see Yonelinas, 2002 for a review). While participants in recall tests retrieve internal memory representations, participants in recognition tests compare the perceptual input of the stimulus with their internal memory representations. Thus, recognition tests involve perceptual as well as memory processes. The perception of the stimulus in recognition memory tests can affect whether the stimulus is recognized as old or new. One excellent example of this is "memory illusion," reported by Jacoby and Whitehouse (1989). They demonstrated that a stimulus preceded by a masked unconscious prime was more likely to be recognized as old, thus, suggesting that increased processing fluency generates increased feelings of familiarity for the stimulus, leading to increased "old" responses.

Furthermore, Jacoby and Whitehouse (1989) reported that participants were more likely to recognize a stimulus as new when it was preceded by a visible prime. They explained this reversion of the priming effect using the idea that participants attribute some parts of perceived fluency to a visible prime and discount fluency for the stimulus. This reversion of the priming effect has been replicated in several studies, but the "fluency discounting" account has been challenged (Klinger, 2001; Higham \& Vokey, 2000; Huber, Clark, Curran, \& Winkielman, 2008). Huber et al. (2008) proposed that the reversal of the priming effect on recognition judgments is explicable without fluency discounting. Their "fluency/disfluency" account suggests that a short prime duration leads to priming and makes stimulus processing fluent, which results in increased "old" responses. In contrast, a longer prime duration leads to habituation and makes stimulus processing disfluent, which results in decreased "old" responses. In short, Jacoby and Whitehouse (1989) assumed that a conscious awareness of the prime induces fluency discounting, which is critical for the reversal of priming, whereas Huber et al. (2008) assumed that stimulus fluency itself is critical, regardless of awareness of the prime. One reason for this controversy may be that the visual awareness of the prime and fluency for the stimulus covary according to the manipulation of prime duration. Thus, alternative methods to manipulate fluency are likely to offer new insights into this topic.

One potent method to manipulate fluency is attentional cueing (e.g., Posner, 1980; Shepherd, Findlay, \& Hockey, 1986; Tipples, 2002). Bayliss, Paul, Cannon, and Tipper (2006) reported that the processing of the target stimulus becomes more fluent when the stimulus location is predicted by attentional cueing. Using attentional cueing, one can manipulate the fluency/disfluency of stimulus processing with keeping a visual awareness of the cue constant. We employed an arrow as an attentional cue because even a non-predictive 
arrow cue automatically affects participants' attention (e.g., Ristic \& Kingstone, 2006; Tipples, 2002). We set cue validity at $50 \%$ to equalize the number of predicted trials and unpredicted trials.

It is important to take note of the results of a study by Rajaram and Geraci (2000). In this study, participants performed a Remember/Know recognition memory test (Tulving, 1985; Gardiner, 1988) while stimulus fluency was manipulated by conceptual priming. The results demonstrated that priming selectively affected "know" responses but did not affect "remember" responses. These results provided strong support for the dual-process theory of recognition memory, which assumes that recollection and familiarity depend on different retrieval mechanisms (Atkinson \& Juola, 1974; Hintzman \& Curran, 1994; Jacoby \& Dallas, 1981; Mandler, 1980; Wixted, 2007).

The selective effect of fluency manipulation on know responses is compatible with two influential models of recognition memory. Under the dual-process signal detection (DPSD) model (Yonelinas, 1994), recollection is considered an all-or-none threshold process, which cannot be affected by fluency manipulation. However, familiarity is considered a continuous variable characterized by a signal detection process that can be affected by fluency manipulation. Alternatively, under the continuous dual-process (CDP) model (Wixted $\&$ Mickes, 2010), both recollection and familiarity are considered continuous variables, additively combined into a single unidimensional memory strength distribution, on which old/new responses depend. Furthermore, the CDP model assumes that remember responses are based on a recollection distribution, and know responses are based on a familiarity distribution. The CDP model is compatible with the results in Rajaram and Geraci (2000), assuming that fluency manipulation affects familiarity distribution but leaves recollection distribution relatively unaffected. We return to this point in the General Discussion.

In the present study, we investigated the effect of attentional cueing on recollection and familiarity using the Remember/Know procedure. If the stimulus-irrelevant attentional cue biases memory, this will be a matter of significant importance in the theoretical understanding of human memory and in our lives outside the laboratory.

\section{Preliminary Experiment}

We conducted a preliminary study to explore appropriate sample size and other task settings (e.g., set size of stimuli, and duration of attentional cue). We expected that attentional cueing would affect participants' recognition bias but not recognition accuracy. Dissimilar to the main experiment, participants were explicitly instructed to attend to the direction of the cue. 


\section{Methods}

\subsection{Participants}

Twenty-two students from Kyoto University aged between 18 and $25(M=21.5, S D=$ 1.97) participated in the preliminary experiment and were paid according to the Kyoto University standard. This sample size was determined by reference to related studies (14 in Dew and Cabeza, 2013; 20-24 in Lucas et al., 2012; 24 in Woollams et al., 2008; 22 in Taylor et al., 2013; 14-20 in Whittlesea and Williams, 2000; 13-21 in Whittlesea and Williams, 2001). Eleven participants were male and 11 were female. All participants had normal color vision. Informed written consent was obtained from participants before the experiment. All data were collected in accordance with the ethical principles of the Japanese Psychological Association. Data from two participants were excluded because one participant exhibited recognition accuracy below chance and the other exhibited no false alarms at all.

\subsection{Stimuli}

The stimuli consisted of 320 color pictures of everyday objects; the pictures were obtained from the Massachusetts Institute of Technology website (http://cvcl.mit.edu/MM/index.html). These stimuli were randomly assigned to each experimental condition (congruent/new, congruent/old, incongruent/new, and incongruent/old) for each participant. The stimuli were displayed on a dark background on a 23-inch computer monitor (I-O DATA, LCD-MF234XPBR) using the software Presentation (Neurobehavioral Systems). Each stimulus was framed in a white window measuring $6.8 \mathrm{x}$ $6.8 \mathrm{~cm}$. A white arrow measuring $1.8 \times 9.4 \mathrm{~cm}$ was used as an attentional cue. To minimize participants' eye movements, the arrow cue was presented in the center of the monitor. The distance between the monitor and participants was $50 \mathrm{~cm}$.

\subsection{Procedure}

Before the experiment described below, each participant completed a practice session, which included four study trials and eight test trials. During the study session, participants were instructed to memorize 160 stimuli presented on the computer monitor. Each stimulus was presented for $1000 \mathrm{~ms}$ with an inter-trial interval of $1500 \mathrm{~ms}$, during which a central fixation cue was presented (Figure 1). After the study session, participants conducted an arithmetic task for 2 minutes.

During the test session, 160 new stimuli and 160 old stimuli were presented in random order. Participants judged whether each stimulus was old or new and reported their awareness of memory according to the Remember/Know procedure (Gardiner, 1988). "Remember" responses indicated that recognition was accompanied by a conscious recollection of the 
specific details of the stimulus or through contextual information from the study session.

"Know" responses indicated that the recognition was supported by a vague feeling of familiarity without conscious recollection of stimulus details or contextual information. Before the experiment, participants were instructed that half of the stimuli in the test session were new and that the other half were old. This instruction was given to prevent participants from being too conservative in judging whether the stimuli were old or new.

During each test trial, after the presentation of the fixation cross for $1500 \mathrm{~ms}$, an arrow was presented for $500 \mathrm{~ms}$ as an attentional cue, followed by the stimulus (Figure 1). In the preliminary study, participants were explicitly instructed to attend to the direction of the attentional cue. The stimulus continued to be presented until participants responded. The stimulus was presented either to the left or the right of the monitor, and its center was $8.2 \mathrm{~cm}$ away from the center of the monitor. If participants provided an "old" response, an alternative ( $\mathrm{R}$ or $\mathrm{K}$ ) was presented and participants made a resultant metamemory judgment. The arrow was equally likely to appear toward the left or the right and was non-predictive as to either the location or the study status (old/new) of the stimulus. Participants experienced a total of 320 trials (80 congruent/new, 80 congruent/old, 80 incongruent/new, and 80 incongruent/old trials) in random order.

After the experiment, participants completed a questionnaire in which they were asked whether they assumed any relationships to exist between the attentional condition (congruent/incongruent) and the study status of the stimulus (old/new).

\section{Data Analysis}

Recollection and familiarity are considered independent or redundant, not mutually exclusive (see Yonelinas, 2002 for a review). However, in the Remember/Know procedure, participants make know responses when a stimulus is familiar and not recollected. Therefore, the raw proportion of know responses underestimates the actual familiarity (Yonelinas \& Jacoby, 1995). To overcome the problem, recollection and familiarity were estimated under the independent Remember/Know assumption (IRK) (Yonelinas \& Jacoby, 1995). Under this assumption, familiarity is calculated by dividing the proportion of know responses by 1 minus the proportion of remember responses [IRK familiarity $=$ pKnow/(1-pRemember)]. These estimates were calculated separately for each condition. Under the IRK assumption, the estimate of recollection and familiarity can have a mutually independent value. Thanks to this, we calculated recognition accuracy $(\mathrm{Pr})$ and recognition bias $(\mathrm{Br})$ (Snodgrass \& Corwin, 1988) separately for recollection and familiarity. Pr is defined as the proportion of hits minus the proportion of false alarms $[\mathrm{Pr}=$ pHit-pFA] and sometimes called the "corrected recognition score." $\mathrm{Br}$ is calculated by dividing the proportion of false alarms by 1 minus $\mathrm{Pr}$ 
$1 \quad[\mathrm{Br}=\mathrm{pFA} /(1-\mathrm{Pr})]$. Furthermore, under the IRK assumption, metamemory (recollection/IRK

2 familiarity) can be used as a factor in ANOVA analysis because independence is assured

3 between factor levels (see Scariano \& Davenport, 1987 with regards to the assumption of

4 independence in ANOVA analysis). Repeated-measures ANOVAs were conducted separately on the false recognition of new stimuli (false alarm), correct recognition of old stimuli (hit), recognition accuracy $(\mathrm{Pr})$, and recognition bias $(\mathrm{Br})$. Partial $\eta^{2}$ was reported to represent effect size. According to Cohen's criteria, partial $\eta^{2}$ of 0.01 is small, 0.06 is moderate, and 0.14 is large (Cohen, 1992). (Please see Richardson (2011) as to the applicability of Cohen's

9 criteria to partial $\eta^{2}$.)

\section{Results and Discussion}

The post-experiment questionnaire showed that no participants assumed the existence of any relationships between the attentional condition and the study status of the stimulus. Recognition memory performances and reaction times for old/new judgments in each condition are summarized in Table 1. We conducted an ANOVA on the false recognition of new stimuli with metamemory (recollection/IRK familiarity) and attentional condition (congruent/incongruent) as within-participant factors. There was a significant main effect for metamemory $\left(F(1,19)=51.90, p<.001\right.$, partial $\left.\eta^{2}=.732\right)$ but no significant main effect for the attentional condition $\left(F(1,19)=0.22, p=.645\right.$, partial $\left.\eta^{2}=.011\right)$. An interaction was nonsignificant $\left(F(1,19)=0.03, p=.865\right.$, partial $\left.\eta^{2}=.002\right)$. These results suggest that attentional cueing did not affect the false recognition of new stimuli. The RT in old/new judgments for new stimuli was significantly faster in the congruent condition than in the incongruent condition $\left(t(19)=3.95, p<.001, d^{\prime}=0.87\right)$.

Next, we conducted an ANOVA on the correct recognition of old stimuli with metamemory and attentional condition as within-participant factors. There was no significant main effect for metamemory $\left(F(1,19)=0.34, p=.568\right.$, partial $\left.\eta^{2}=.017\right)$ but a significant main effect for the attentional condition $\left(F(1,19)=6.28, p=.021\right.$, partial $\left.\eta^{2}=.248\right)$ was observed. An interaction was nonsignificant $\left(F(1,19)=0.25, p=.620\right.$, partial $\left.\eta^{2}=.013\right)$. The results indicate that the correct recognition of old stimuli was more frequent in the incongruent condition than in the congruent condition. The RT in old/new judgments for old stimuli was significantly faster in the congruent condition than in the incongruent condition $(t$ $\left.(19)=5.02, p<.001, d^{\prime}=1.12\right)$.

We also analyzed recognition accuracy (Pr). An ANOVA showed a significant main effect for metamemory $\left(F(1,19)=7.61, p=.013\right.$, partial $\left.\eta^{2}=.286\right)$ and the attentional condition $\left(F(1,19)=4.58, p=.045\right.$, partial $\left.\eta^{2}=.194\right)$. An interaction was nonsignificant $(F$ $(1,19)=0.25, p=.626$, partial $\left.\eta^{2}=.013\right)$. These results suggest that recognition accuracy 
was higher in the incongruent condition than in the congruent condition.

Finally, we conducted an ANOVA on recognition bias (Br) with metamemory and attentional condition as within-participant factors. A significant main effect for metamemory was found $\left(F(1,19)=20.64, p<.001\right.$, partial $\left.\eta^{2}=.521\right)$, but no significant main effect was found for the attentional condition $\left(F(1,19)=0.571, p=.459\right.$, partial $\left.\eta^{2}=.029\right)$. An interaction was nonsignificant $\left(F(1,19)=0.14, p=.711\right.$, partial $\left.\eta^{2}=.007\right)$. These results suggest that attentional cueing did not affect participants' recognition bias.

Notably, however, additional analyses without the IRK assumption showed a different pattern of results than that described above (see the appendix for details). ${ }^{\text {i }}$ Simply stated, attentional cueing did not have significant effects on participants' raw responses but did have effects on recognition measures estimated from those responses under the IRK assumption. The present findings must be interpreted carefully. In any case, contrary to our expectation, attentional cueing did not affect participants' recognition bias. Although it is unclear why this pattern of results arose, one possibility is that the participants might try to remain unaffected by attentional manipulation in recognition judgments when they consciously shift their attention on their own. To explore this possibility, we conducted the main experiment, in which participants were not explicitly instructed to attend to the direction of the arrow. As several significant effects of attentional cueing were observed in the preliminary study, we used the same task settings (e.g., number of participants, set size of stimuli, duration of attentional cue) in the main experiment.

\section{Main Experiment}

\subsection{Methods}

\subsubsection{Stimuli and procedure}

The stimuli and procedure were the same as that of the preliminary experiment, except that no instruction was given regarding the attentional cue; participants were not explicitly instructed to attend to the direction of the cue. Nevertheless, the arrow cue was shown to automatically change the attentional states of participants (e.g., Bayliss et al., 2006; Tipples, 2002).

\subsection{Participants}

In all, 22 students from Kyoto University aged between 19 and 24 years $(M=21.2$, $S D=1.47)$ participated in the experiment and were paid according to the Kyoto University standard. Fifteen participants were male and 7 were female. All participants had normal color vision. Informed written consent was obtained from participants before the experiment. All data were collected in accordance with the ethical principles of the Japanese Psychological 
Association.

\subsection{Results}

The post-experiment questionnaire showed that no participants assumed the existence of any relationships between the attentional condition and the study status of the stimulus. Recognition memory performances and reaction times for old/new judgments in each condition are summarized in Table 2 . Recollection and familiarity were estimated under the IRK assumption.

First, we conducted an ANOVA on the false recognition of new stimuli with metamemory (recollection/IRK familiarity) and attentional condition (congruent/incongruent) as within-participant factors (Figure 2A). A significant main effect was found for metamemory $\left(F(1,21)=82.78, p<.001\right.$, partial $\left.\eta^{2}=.798\right)$, but no significant main effect was found for the attentional condition $\left(F(1,21)=3.25, p=.086\right.$, partial $\left.\eta^{2}=.134\right)$. An interaction between these two factors was significant $\left(F(1,21)=4.44, p=.047\right.$, partial $\eta^{2}$ $=.175)$. A simple main effect analysis revealed that the estimate of IRK familiarity was significantly higher in the incongruent condition than in the congruent condition $(F(1,42)=$ $7.38, p=.0096$, partial $\eta^{2}=.260$ ), which suggests that participants exhibited familiarity-based false recognition more frequently in the incongruent condition. A post hoc power analysis revealed that the power to detect this simple main effect was 0.98 under the current settings ( sample size $=22$ and significance level $=0.05$ ). No significant difference between the estimate of recollection in the congruent condition and in the incongruent condition was seen $\left(F(1,42)=0.02, p=.896\right.$, partial $\left.\eta^{2}=.001\right)$. In addition, the RT in old/new judgments for new stimuli was significantly faster in the congruent condition than in the incongruent condition $\left(t(21)=3.45, p=.002, d^{\prime}=0.74\right)$.

Second, we conducted an ANOVA on the correct recognition of old stimuli with metamemory and attentional condition as within-participant factors (Figure 2B). No significant main effect was found for metamemory $\left(F(1,21)=0.002, p=.965\right.$, partial $\eta^{2}$ $=.0001)$, nor was a significant main effect found for the attentional condition $(F(1,21)=$ $1.23, p=.281$, partial $\left.\eta^{2}=.055\right)$. An interaction between metamemory and the attentional condition was also nonsignificant $\left(F(1,21)=1.41, p=.249\right.$, partial $\left.\eta^{2}=.063\right)$. These results suggest that attentional cueing did not affect the correct recognition of old stimuli. The RT in old/new judgments for old stimuli was significantly faster in the congruent condition than in the incongruent condition $\left(t(21)=2.94, p=.008, d^{\prime}=0.63\right)$.

Third, we analyzed recognition accuracy (Pr) under the IRK assumption (Table 2). We conducted an ANOVA on Pr with metamemory and attentional condition as 
within-participant factors. A significant main effect for metamemory was found $(F(1,21)=$ $6.78, p=.017$, partial $\left.\eta^{2}=.244\right)$, but no significant main effect was found for the attentional condition $\left(F(1,21)=0.21, p=.651\right.$, partial $\left.\eta^{2}=.010\right)$. Furthermore, no significant interaction between metamemory and the attentional condition was seen $(F(1,21)=0.02, p$ $=.893$, partial $\left.\eta^{2}=.001\right)$. The results suggest no significant effect of attentional cueing on recognition accuracy.

Finally, we analyzed recognition bias (Br) under the IRK assumption (Table 2). We conducted an ANOVA on Br with metamemory and attentional condition as within-participant factors. A significant main effect for metamemory was found $(F(1,21)=$ $77.70, p<.001$, partial $\left.\eta^{2}=.787\right)$, but no significant main effect was found for the attentional condition $\left(F(1,21)=2.79, p=.110\right.$, partial $\left.\eta^{2}=.117\right)$. The interaction between metamemory and attentional condition approached significance $\left(F(1,21)=3.33, p=.082\right.$, partial $\eta^{2}$ $=.137)$. A simple main effect analysis revealed that familiarity-based $\mathrm{Br}$ was higher in the incongruent condition $\left(F(1,42)=5.63, p=.022\right.$, partial $\left.\eta^{2}=.211\right)$, suggesting that familiarity-based recognition was more liberal in the incongruent condition. A post hoc power analysis revealed that the power to detect this simple main effect was 0.95. Attentional condition did not significantly affect recollection-based $\operatorname{Br}(F(1,42)=0.24, p=.624$, partial $\left.\eta^{2}=.011\right)$

In summary, the present results reveal that familiarity-based false recognition increased by incongruent cueing in testing. This increased false recognition was associated with participants' liberal recognition bias, not with decreased recognition accuracy. Thus, increased familiarity-based false recognition in the incongruent condition cannot be attributed to the possibility that participants could not accurately recognize the stimulus due to inattention. Note that additional analyses without the IRK assumption showed a consistent pattern of results with the above-mentioned main results (see the appendix for details). ${ }^{\mathrm{ii}}$

\section{General Discussion}

The main experiment provides the novel finding that stimulus-irrelevant attentional cues bias recognition memory judgments and induce familiarity-based false recognition. Although we did not explicitly instruct participants to attend to the direction of the arrow cue, it automatically affected the fluency of stimulus processing (reflected in significant RT difference). In the incongruent condition, participants may attribute part of the perceived disfluency to the attentional cue and overestimate the fluency of the stimulus, thus leading to more liberal familiarity-based recognition judgments. On the other hand, in the congruent condition, participants may attribute some parts of the perceived fluency to the attentional cue rather than to the study session. As a result, they might underestimate the fluency of the 
1 stimulus and exhibit more conservative familiarity-based recognition judgments. Unlike the

2 prime used in previous studies, the attentional cue in the present study was not perceptually

3 or semantically related to the stimulus. Nevertheless, participants may still attribute the

4 perceived fluency or disfluency to the cue. We did not provide any instruction about the attentional cue to participants. Moreover, participants reported in the questionnaire that they did not assume any relationships to exist between the attentional condition (congruent/incongruent) and the study status of the stimulus (old/new). Therefore, attentional cueing might induce unintentional processing about the source of fluency, consequently causing bias in participants' recognition memory. This explanation accords with the fluency discounting account introduced by Jacoby and Whitehouse (1989) but is inconsistent with the fluency/disfluency account proposed by Huber et al. (2008). If stimulus fluency itself is critical for memory bias, recognition judgments would have been more liberal in the congruent condition; however, the opposite occurred in this study.

The present findings may also be explained in the context of the discrepancy-attribution theory (e.g., Whittlesea \& Williams, 1998, 2000, 2001). This theory assumes that a feeling of familiarity arises when actual fluency is discrepant from expected fluency (e.g., seeing one's spouse in the subway rather than in the kitchen). In the present study, expected fluency may be lower in the incongruent condition than in the congruent condition. Unexpectedly high fluency in the incongruent condition may lead to a strong feeling of familiarity, leading to participants exhibiting more old responses. Another possible speculation stems from the effect of selective attention. Fischer and Whitney (2009) reported that spatially directed attention narrows the tuning of population-coded position representations in the primary visual cortex. The narrowed representation of the stimulus may inhibit the diffusional activation of delusive information and may reduce familiarity-based false recognition in the congruent condition. However, this account cannot explain why attentional cueing induces an overall shift of recognition bias in familiarity-based recognition judgments.

Attentional cueing only affected the estimate of familiarity; the estimate of recollection was not affected. As we mentioned in the introduction, the pattern of the results is compatible with two influential models of dual-process recognition memory. In the DPSD model (Yonelinas, 1994), recollection is thought to depend on an all-or-none threshold process, whereas familiarity is a continuous variable that can be influenced by fluency manipulation. In the CDP model (Wixted \& Mickes, 2010), recollection and familiarity are considered to depend on two respective signal distributions. If we assume that attentional cueing affects familiarity distribution with recollection distribution relatively unaffected, this model is also compatible with the present results. Nevertheless, as recollection is understood 
as a graded phenomenon under the CDP model, there is room for recollection to be affected by fluency manipulation. Consistent with this, Lucas et al. (2012) reported that masked priming affected both remember and know responses. Furthermore, Kurilla and Westerman (2008) reported that masked priming affected individual ratings of recollection and familiarity. However, these empirical findings do not instantly allow for rejection of the DPSD model (Yonelinas, 1994), because Remember/Know responses and individual ratings may not be process-pure measures of recollection and familiarity; these putative measures of recollection could partially reflect familiarity and thus be affected by fluency manipulation.

Furthermore, attentional cueing only affected the false familiarity for new stimuli; the correct familiarity for old stimuli was not affected. In accordance with this evidence, several studies demonstrated that the fluency effect on recognition judgments was more robust for new rather than old stimuli (e.g., Tunney \& Fernie, 2007; Westerman, 2008; Whittlesea \& Williams, 2001). One possibility is that the estimate of familiarity for old stimuli may be to some extent contaminated with recollection from the study session, and thus less affected by attentional cueing. Several studies support the idea that know responses entail some amount of recollection (Hicks, Marsh, \& Ritschel, 2002; Johnson et al., 2009; Wais, Mickes, \& Wixted, 2008). However, the pattern of results is not consistent among the literature reporting that fluency manipulation affects responses for both old and new stimuli (e.g., Dew \& Cabeza, 2013; Rajaram \& Geraci, 2000).

The present study shows that stimulus-irrelevant attentional cueing biases recognition memory. This has significant implications for everyday situations, in that the incidental manipulation of attention could occur in many situations in our daily lives. Imagine that something distracts your attention from a to-be-perceived situation. In this case, you may unintentionally overestimate the perceived fluency for the situation and falsely recognize it as one you have experienced before. Déjà vu may be one manifestation of this bias. Moreover, this kind of memory bias is of serious concern in some cases, such as eyewitness testimony. To explore the generality and applicability of the effect reported here, additional studies using variable materials would be helpful. In particular, the stimuli of social importance, such as human faces or lexical words, may be suitable for further investigation.

Lastly, it is important to note several limitations in the present study. One issue regards the difference in results between the preliminary and main experiments. The preliminary results showed that the attentional cue did not change participants' recognition bias when participants explicitly shifted their attention. One could speculate that unintentional processing about the source of fluency might not occur when attention is voluntarily shifted. It might also be possible that participants try to remain unaffected by 
attentional manipulation when they consciously shift their attention on their own, and intentional memory processing dominates over unintentional processing about the source of fluency. Consistent with these speculations, participants exhibited slower RTs in the preliminary experiment than in the main experiment (though this is a between-participant comparison), suggesting that they depended more heavily on intentional memory processing. Future research is needed to explore the factors that modulate the effect of attentional cueing on recognition judgments. Another issue is that there were no control conditions and thus we could only conduct relative comparisons between the congruent and incongruent conditions.

Establishing an appropriate control condition enables us to separately assess the effect of congruent and incongruent cues. Finally, it should be noted that the mechanism for attentional cueing to affect processing fluency may differ in quality from that for other experimental manipulations (e.g., repetition priming, conceptual priming, changes in perceptual clarity). Differences and similarities of the effect of these quantitatively different experimental manipulations on recognition judgments remain open for further investigation.

\section{Conclusion}

Attentional cueing biases familiarity-based recognition judgments. This effect is well explained by the hypothesis regarding unintentional processing about the source of fluency. As attentional cueing is a simple yet powerful method for manipulating fluency, it would be of great service for future research to further elucidate the contribution that processing fluency makes to memory processes.

\section{Acknowledgments}

This work was supported by a JSPS Grant-in-Aid for scientific research (22220003) and a Grant-in-Aid for JSPS Fellows (15J06742). 


\section{References}

Atkinson, R. C., \& Juola, J. F. (1974). Search and decision processes in recognition memory. In D. H. Krantz, R. C. Atkinson, \& P. Suppes (Eds.), Contemporary developments in mathematical psychology (pp. 243-290). San Francisco: Freeman.

Bayliss, A. P., Paul, M. A., Cannon, P. R., \& Tipper, S. P. (2006). Gaze cuing affective judgments of objects: I like what you look at. Psychonomic Bulletin \& Review, 13(6), 1061-1066.

Cohen, J. (1992). A power primer. Psychological Bulletin, 112(1), 155-159.

Dew, I. T. Z., \& Cabeza, R. (2013). A broader view of perirhinal function: From recognition memory to fluency-based decisions. The Journal of Neuroscience, 33(36), 14466-14474.

Fischer, J., \& Whitney, D. (2009). Attention narrows position tuning of population responses in V1. Current Biology, 19(16), 1356-1361.

Gardiner, J. M. (1988). Functional aspects of recollective experience. Memory \& Cognition, 16(4), 309-313.

Hicks, J. L., Marsh, R. L., \& Ritschel, L. (2002). The role of recollection and partial information in source monitoring. Journal of Experimental Psychology: Learning, Memory, and Cognition, 28, 503-508.

Higham, P. A., \& Vokey, J. R. (2000). Judgment heuristics and recognition memory: prime identification and target-processing fluency. Memory \& Cognition, 28(4), 574-584.

Hintzman, D. L., \& Curran, T. (1994). Retrieval dynamics of recognition and frequency judgments: Evidence for separate processes of familiarity and recall. Journal of Memory and Language, 33(1), 1-18.

Huber, D. E., Clark, T. F., Curran, T., \& Winkielman, P. (2008). Effects of repetition priming on recognition memory: Testing a perceptual fluency-disfluency model. Journal of Experimental Psychology: Learning, Memory, and Cognition, 34(6), 1305-1324.

Jacoby, L. L., \& Dallas, M. (1981). On the relationship between autobiographical memory and perceptual learning. Journal of Experimental Psychology: General, 110(3), 306-340.

Jacoby, L. L., \& Whitehouse, K. (1989). An illusion of memory: False recognition influenced by unconscious perception. Journal of Experimental Psychology. General, 118(2), $126-135$.

Johnson, J. D., McDuff, S. G. R., Rugg, M. D., \& Norman, K. A. (2009). Recollection, familiarity, and cortical reinstatement: A multivoxel pattern analysis. Neuron, 63, 697-708.

Klinger, M. R. (2001). The roles of attention and awareness in the false recognition effect. The American Journal of Psychology, 114(1), 93-114. 
Kurilla, B. P., \& Westerman, D. L. (2008). Processing fluency affects subjective claims of recollection. Memory \& Cognition, 36(1), 82-92.

Lucas, H. D., Taylor, J. R., Henson, R. N., \& Paller, K. A. (2012). Many roads lead to recognition: electrophysiological correlates of familiarity derived from short-term masked repetition priming. Neuropsychologia, 50(13), 3041-3052.

Mandler, G. (1980). Recognizing: The judgment of previous occurrence. Psychological Review, 87(3), 252-271.

Posner, M. I. (1980). Orienting of attention. Quarterly Journal of Experimental Psychology, $32(1), 3-25$.

Rajaram, S., \& Geraci, L. (2000). Conceptual fluency selectively influences knowing. Journal of Experimental Psychology: Learning, Memory \& Cognition, 26(4), 1070-1074.

Richardson, J. T. E. (2011). Eta squared and partial eta squared as measures of effect size in educational research. Educational Research Review, 6(2), 135-147.

Ristic, J., \& Kingstone, A. (2006). Attention to arrows: Pointing to a new direction. The Quarterly Journal of Experimental Psychology, 59(11), 1921-1930.

Scariano, S. M., \& Davenport, J. M. (1987). The effects of violations of independence assumptions in a one-way ANOVA. The American Statistician, 41(2), 123-129.

Shepherd, M., Findlay, J. M., \& Hockey, R. J. (1986). The relationship between eye movements and spatial attention. Quarterly Journal of Experimental Psychology Section A: Human Experimental Psychology, 38(3), 475-491.

Snodgrass, J. G., \& Corwin, J. (1988). Pragmatics of measuring recognition memory: Applications to dementia and amnesia. Journal of Experimental Psychology: General, 117(1), 34-50.

Taylor, J. R., Buratto, L. G., \& Henson, R.N. (2013). Behavioral and neural evidence for masked conceptual priming of recollection. Cortex, 49(6), 1511-1525.

Tipples, J. (2002). Eye gaze is not unique: Automatic orienting in response to uninformative arrows. Psychonomic Bulletin \& Review, 9(2), 314-318.

Tulving, E. (1985). Memory and consciousness. Canadian Psychology 26(1), 1-12.

Tunney, R. J., \& Fernie, G. (2007). Repetition priming affects guessing not familiarity. Behavioral and Brain Functions, 3(1), 40-46.

Wais, P. E., Mickes, L., \& Wixted, J. T. (2008). Remember/know judgments probe degrees of recollection. Journal of Cognitive Neuroscience, 20, 400-405.

Westerman, D. L. (2008). Relative fluency and illusions of recognition memory. Psychonomic Bulletin \& Review, 15(6), 1196 -1200.

Whittlesea, B.W.A., \& Williams, L. D. (1998). Why do strangers feel familiar, but friends don't? A discrepancy-attribution account of feelings of familiarity. Acta Psychologica, 98(2-3), 141-165. 
Whittlesea, B. W., \& Williams, L. D. (2000). The source of feelings of familiarity: The discrepancy-attribution hypothesis. Journal of Experimental Psychology: Learning, Memory, and Cognition, 26(3), 547-565.

Whittlesea, B. W., \& Williams, L. D. (2001). The discrepancy-attribution hypothesis: I. The heuristic basis of feelings of familiarity. Journal of Experimental Psychology: Learning, Memory, and Cognition, 27(1), 3-13.

Wixted, J. T. (2007). Dual-process theory and signal detection theory of recognition memory. Psychological Review, 114(1), 152-176.

Wixted, J. T., \& Mickes, L. (2010).A continuous dual-process model of remember/know judgments. Psychological Review, 117(4), 1025-1054.

Woollams, A. M., Taylor, J. R., Karayanidis, F., \& Henson, R. N. (2008). Event-related potential associated with masked priming of test cues reveal multiple potential contributions to recognition memory. Journal of Cognitive Neuroscience, 20(6), 1114-1129.

Yonelinas, A. P. (1994). Receiver-operating characteristics in recognition memory: Evidence for a dual-process model. Journal of Experimental Psychology: Learning, Memory, and Cognition, 20(6), 1341-1354.

Yonelinas, A. P. (2002). The nature of recollection and familiarity: A review of 30 years of research. Journal of Memory and Language, 46(3), 441-517.

Yonelinas, A. P., \& Jacoby, L. L. (1995). The relation between remembering and knowing as bases for recognition: Effects of size congruency. Journal of Memory and Language, 34(5), 622-643. 
1

2 Table 1

3 Mean recognition performances and mean reaction time in the preliminary experiment.

\begin{tabular}{|c|c|c|c|c|c|c|c|c|}
\hline & \multicolumn{4}{|l|}{ Congruent } & \multicolumn{4}{|c|}{ Incongruent } \\
\hline & Old stimuli & New stimuli & $\operatorname{Pr}$ & $\mathrm{Br}$ & Old stimuli & New stimuli & $\operatorname{Pr}$ & $\mathrm{Br}$ \\
\hline Recollection & $0.53(0.18)$ & $0.03(0.04)$ & $0.50(0.20)$ & $0.06(0.07)$ & $0.55(0.19)$ & $0.02(0.03)$ & $0.53(0.20)$ & $0.07(0.15)$ \\
\hline pKnow & $0.24(0.12)$ & $0.12(0.07)$ & & & $0.23(0.10)$ & $0.12(0.07)$ & & \\
\hline IRK Familiarity & $0.49(0.12)$ & $0.13(0.08)$ & $0.36(0.16)$ & $0.20(0.10)$ & $0.53(0.12)$ & $0.13(0.08)$ & $0.40(0.15)$ & $0.20(0.10)$ \\
\hline RT (ms) & $1325(258)$ & 1367 (225) & & & $1429(278)$ & $1505(277)$ & & \\
\hline
\end{tabular}

$4 S D$ is shown in parenthesis.

5

6

7

8

9

10

11

12

13

14

15

16

17

18

19

20

21

22

23

24

25

26

27

28

29

30 
1

2 Table 2

3 Mean recognition performances and mean reaction time in the main experiment.

\begin{tabular}{|c|c|c|c|c|c|c|c|c|}
\hline & \multicolumn{4}{|l|}{ Congruent } & \multicolumn{4}{|c|}{ Incongruent } \\
\hline & Old stimuli & New stimuli & $\operatorname{Pr}$ & $\mathrm{Br}$ & Old stimuli & New stimuli & $\operatorname{Pr}$ & $\mathrm{Br}$ \\
\hline Recollection & $0.50(0.17)$ & $0.03(0.04)$ & $0.47(0.18)$ & $0.05(0.06)$ & $0.51(0.20)$ & $0.03(0.03)$ & $0.49(0.21)$ & $0.06(0.06)$ \\
\hline pKnow & $0.25(0.13)$ & $0.14(0.07)$ & & & $0.26(0.13)$ & $0.16(0.07)$ & & \\
\hline IRK Familiarity & $0.49(0.17)$ & $0.15(0.07)$ & $0.35(0.15)$ & $0.23(0.12)$ & $0.53(0.19)$ & $0.17(0.07)$ & $0.36(0.19)$ & $0.28(0.13)$ \\
\hline RT (ms) & $1231(249)$ & $1268(235)$ & & & $1281(267)$ & $1335(278)$ & & \\
\hline
\end{tabular}

$4 \quad S D$ is shown in parenthesis.

5

6

7

8

9

10

11

12

13

14

15

16

17

18

19

20

21

22

23

24

25

26

27

28

29

30

31

32 
1

2

3

4

5

6

7

8

9

10

11

12

13

14

15

16

17

18

19

20

21

22

23

24

25

26

27

28

29

30

31

32

33

34

35

36

37

38
Study

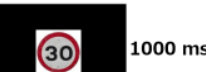

Congruent condition

Test
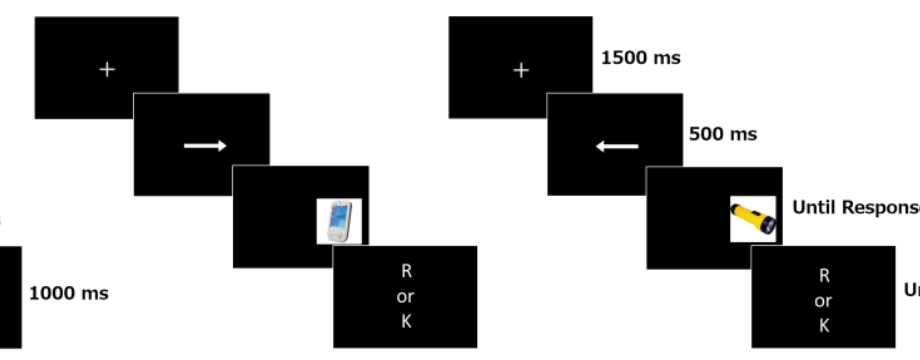

Until Response

Figure 1 Schematic diagrams of the experimental procedure. 
1

2

3

4

5

6

7

8

9

10

11

12

13

14

15

16

17

18

19

20

21

22

23

24

25

26

27

28

29

30

31

32

33

34

35

36

37

38
(A)

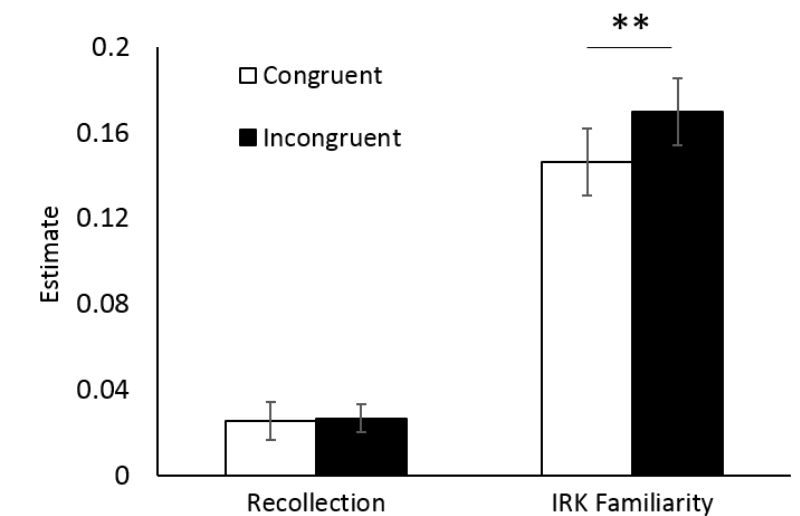

(B)

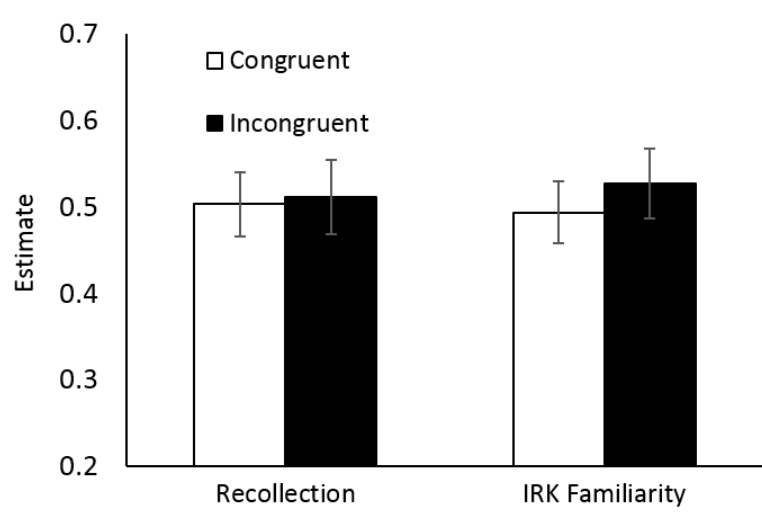

Figure 2 (A) Estimates of false recollection and false IRK familiarity. (B) Estimates of correct recollection and correct IRK familiarity. Error bars indicate the standard error of the mean. $* *$ indicates $p<.01$. 


\section{${ }^{i}$ Additional analyses for the preliminary experiment}

Additional analyses were conducted using the raw proportion of remember and know responses without the IRK procedure (Table 1). An ANOVA on the proportion of responses for new stimuli was conducted with metamemory response (remember/know) and attentional condition

(congruent/incongruent) as within-participant factors. A significant main effect was found for metamemory response $\left(F(1,19)=51.31, p<.001\right.$, partial $\left.\eta^{2}=.730\right)$, but no significant main effect was found for attentional condition $\left(F(1,19)=0.14, p=.071\right.$, partial $\left.\eta^{2}=.007\right)$. An interaction between these two factors was not significant $\left(F(1,19)=0.002, p=.963\right.$, partial $\left.\eta^{2}=.0001\right)$.

Next, we conducted an ANOVA on the proportion of responses for old stimuli. A significant main effect was found for metamemory response $\left(F(1,19)=22.91, p<.001\right.$, partial $\left.\eta^{2}=.547\right)$ and a main effect for attentional condition was approaching significance $\left(F(1,19)=3.39, p=.081\right.$, partial $\left.\eta^{2}=.152\right)$. An interaction between these two factors was nonsignificant $\left(F(1,19)=1.60, p=.222\right.$, partial $\left.\eta^{2}=.078\right)$.

Further, we analyzed signal detection measures ( $\mathrm{d}^{\prime}$ and $\mathrm{C}$ ) for old/new responses pooled across metamemory responses. Response accuracy $\left(\mathrm{d}^{\prime}\right)$ in the congruent condition $(M=1.90, S D=0.68)$ was not significantly different from that in the incongruent condition $(M=2.02, S D=0.77)(t(19)=1.30, p=.211$, $\left.d^{\prime}=0.29\right)$. Moreover, response bias $(\mathrm{C})$ in the congruent condition $(M=0.17, S D=0.23)$ was not significantly different from that in the incongruent condition $(M=0.13, S D=0.25)(t(19)=1.40, p=.176$, $d^{\prime}=0.31$.

In short, these additional analyses showed that attentional cueing did not have significant effects on participants' raw responses without the IRK procedure.

\section{ii Additional analyses for the main experiment}

To follow up the main results, additional analyses were conducted using the raw proportion of remember and know responses without the IRK procedure (Table 2). An ANOVA on the proportion of responses for new stimuli was conducted with metamemory response (remember/know) and attentional condition (congruent/incongruent) as within-participant factors. A significant main effect was found for metamemory response $\left(F(1,21)=75.63, p<.001\right.$, partial $\left.\eta^{2}=.783\right)$, but no significant main effect was found for attentional condition $\left(F(1,21)=3.48, p=.076\right.$, partial $\left.\eta^{2}=.142\right)$. An interaction between these two factors was nearly significant $\left(F(1,21)=4.44, p=.054\right.$, partial $\left.\eta^{2}=.166\right)$. A simple main effect analysis revealed that the proportion of know responses was significantly higher in the incongruent condition than in the congruent condition $\left(F(1,42)=7.50, p=.009\right.$, partial $\left.\eta^{2}=.263\right)$. No significant difference between the proportion of remember responses in the congruent condition and that in the incongruent condition was seen $\left(F(1,42)=0.02, p=.892\right.$, partial $\left.\eta^{2}=.001\right)$.

Next, we conducted an ANOVA on the proportion of responses for old stimuli. A significant main effect was found for metamemory response $\left(F(1,21)=16.29, p=.001\right.$, partial $\left.\eta^{2}=.437\right)$. There was no significant main effect for attentional condition $\left(F(1,21)=0.80, p=.382\right.$, partial $\left.\eta^{2}=.037\right)$. An interaction between these two factors was nonsignificant $\left(F(1,21)=0.01, p=.906\right.$, partial $\left.\eta^{2}=.001\right)$.

To further support the main findings, we analyzed signal detection measures $\left(\mathrm{d}^{\prime}\right.$ and $\left.\mathrm{C}\right)$ for old/new responses pooled across metamemory responses. Response accuracy $\left(\mathrm{d}^{\prime}\right)$ in the congruent condition $(M=1.75, S D=0.53)$ was not significantly different from that in the incongruent condition $(M=$ $1.73, S D=0.69)\left(t(21)=0.28, p=.782, d^{\prime}=0.06\right)$. However, response bias $(C)$ in the congruent condition $(M=0.16, S D=0.25)$ was marginally significantly higher than that in the incongruent condition $(M=0.06$, $S D=0.26)\left(t(21)=1.93, p=.067, d^{\prime}=0.41\right)$.

In sum, these additional results are consistent with the main results under the IRK assumption.

$\dagger$

As the above-described ANOVAs include the mutually exclusive metamemory response (remember/know) as a factor, the assumption of independence is violated, which can lead to biased Type I and Type II error rates (see Scariano \& Davenport, 1987). 